Artigo original

Hegemonia - Revista Eletrônica do Programa de Mestrado em Direitos Humanos, Cidadania e Violência/Ciência Política do Centro Universitário Unieuro

ISSN: 1809-1261

UNIEURO, Brasília, número 26, Janeiro a Junho de 2019, pp. 66-94.

Recebido em: 29/08/2018

Avaliado em: 5/09/2018

Aprovado em: 15/10/2018

\title{
GESTÃO PÚBLICA, SAÚDE COLETIVA E MEIO AMBIENTE NO BRASIL: UM ENSAIO DE INTERPRETAÇÃO
}

Aldira Guimarães Duarte, ${ }^{1}$ Carlos Federico Domínguez Avila, ${ }^{2}$ e Aldene Dantas ${ }^{3}$

Resumo: O objetivo deste artigo é analisar e interpretar o contexto atual das políticas públicas ambientais, assim como os desafios e possíveis cenários que podem se apresentar tanto no relacionado ao quadro ambiental, como também na atuação e empregabilidade do profissional sanitarista. A ideia é abrir o debate e ampliar a discussão sobre o tema tendo a promoção da qualidade da vida humana como princípio fundamental.

Palavras-chave: Meio ambiente; Saúde coletiva; Gestão pública; Brasil.

Abstract: The aim of this article is to analyze and interpret the current context of environmental and health public policies. Also, the paper explores the labor and employability of the professional of health management. The idea is to open the debate and the discussion on the theme, with the promotion of the quality of human life as a fundamental principle.

Keywords: Environment; Public health; Public management; Brazil.

Introdução

Este artigo aborda a problemática ambiental e seu impacto na saúde da população. A partir de uma revisão bibliográfica, discute a incorporação da temática saúde e ambiente no campo de conhecimento, práticas e interconexão com a saúde coletiva. Traz um panorama histórico do contexto da interface entre meio ambiente e saúde, e de como as práticas sustentáveis podem interferir positivamente na qualidade de vida e saúde da população e das futuras gerações.

\footnotetext{
${ }^{1}$ Doutora em Ciências da Saúde e docente da Universidade de Brasília.

2 Doutor em História e docente do Programa de Mestrado em Ciências Políticas do Centro Universitario Unieuro.

${ }^{3}$ Mestranda em Biotecnologia pela Universidade de Brasília.
} 
Artigo original

Hegemonia - Revista Eletrônica do Programa de Mestrado em Direitos Humanos, Cidadania e Violência/Ciência Política do Centro Universitário Unieuro

ISSN: 1809-1261

UNIEURO, Brasília, número 26, Janeiro a Junho de 2019, pp. 66-94.

A preocupação com o tema não é recente. Desde a antiguidade o homem compreendeu que a contaminação do meio ambiente podia transmitir doenças. Mas, foi a partir do século XVIII que o problema se agravou devido principalmente ao crescimento industrial e o processo de urbanização. A falta de infraestrutura na qual os camponeses foram submetidos quando migraram para as cidades em busca de trabalho, desencadeou vários problemas de saúde pública e agressão ao meio ambiente. Essa desordem, ocasionada pela expansão das atividades industriais que atraiu muitas pessoas para as cidades, provocou mudanças drásticas na natureza, onde se desenvolveram diversos problemas ambientais como a poluição, desmatamento, redução na biodiversidade, mudanças climáticas, produção excessiva de lixo e de esgoto (GUERRA e CUNHA, 2006).

Os colonizadores portugueses foram de fato, os primeiros a se preocuparem com as questões sanitárias no Brasil, observando a grande disseminação de doenças entre a população, período que deu início à instalação dos primeiros serviços de saúde pública. $\mathrm{O}$ cuidado com quintais e limpeza das ruas, bem como a fiscalização de portos, foram algumas das questões levantadas na regulamentação de leis. Somente a partir de 1888, se começa a pensar nos sistemas de canalização de água e esgoto (KARIATSUMARI, 2007).

O tema do saneamento básico assumiu uma relevância ainda maior no século XX. Entre os anos de 1960 e 1980, os parâmetros físicos, químicos e bacteriológicos das águas foram definidos por meio de legislações estaduais e em âmbito federal. O principal objetivo era proporcionar avanços nas áreas de abastecimento de água e de esgotamento sanitário no país, que resultaria na redução das taxas de mortalidade.

A Lei 005027 de 14 de Junho 1966, por exemplo, estabelece que as atividades necessárias à proteção da saúde da comunidade compreenderiam basicamente: a) controle da água; b) controle do sistema de eliminação de dejetos; c) controle do lixo; d) e outros problemas relacionados com o saneamento do meio ambiente; e) higiene da habitação e dos logradouros públicos; f) combate aos insetos, roedores e outros animais de risco sanitário; g) prevenção das doenças evitáveis e de outros agravos a saúde; h) higiene do trabalho (BRASIL, 1966).

Seja como for, ainda se observam condições muito desfavoráveis, principalmente em cidades do interior do país e até nas periferias das capitais. Apesar da cobertura de saneamento básico com oferta de água tratada ter aumentado significativamente nas últimas 
Artigo original

Hegemonia - Revista Eletrônica do Programa de Mestrado em Direitos Humanos, Cidadania e Violência/Ciência Política do Centro Universitário Unieuro

ISSN: 1809-1261

UNIEURO, Brasília, número 26, Janeiro a Junho de 2019, pp. 66-94.

décadas, as iniquidades sociais em saúde ainda permanecem vigentes nos municípios mais pobres do Brasil. Em 2013, de acordo com os dados do Sistema Nacional de Informações sobre Saneamento - SNIS, $82,5 \%$ da população do país era abastecida com água tratada. Contudo, aproximadamente $18 \%$ da população, mais de 35 milhões de brasileiros, não usufruíam desses serviços. Em relação à coleta de esgotos, apenas 48,6\% da população recebiam esses serviços, totalizando quase 100 milhões de brasileiros desassistidos por esse tipo de saneamento. A situação se agravou em relação aos esgotos tratados, que segundo os dados oficiais, correspondiam apenas a 39\% do total. Por via de consequência, aproximadamente $60 \%$ dos esgotos não tratados, acabam sendo despejados diariamente na natureza, contaminado o meio ambiente e gerando ameaças para a saúde pessoas (SNIS, 2014).

Ao trazer esta realidade para as 100 maiores cidades do país, onde vivem $40 \%$ da população brasileira, nota-se que as situações mais críticas permanecem em cidades das regiões Norte e Nordeste, com várias capitais ocupando as piores colocações. O Sudeste é a região que concentra a maior parte das cidades com boas condições em saneamento. De fato, 14 das 20 melhores cidades brasileiras em saneamento, se localizam nessa região (SNIS, 2014). Assim, justifica-se a presença de melhores indicadores de saúde nas regiões com melhor cobertura de saneamento.

Sabe-se que o comprometimento dos fluxos de água, tanto em quantidade, quanto em qualidade, a falta de oferta da rede de esgoto e a coleta de lixo, influenciam diretamente no processo de degradação do meio ambiente e consequentemente na prevalência de doenças evitáveis que comprometem a qualidade de vida do ser humano em particular, e a preservação dos recursos naturais de maneira geral.

Nesse sentido, busca-se neste capítulo oferecer informações gerais que possam servir de suporte para tomada de decisões mais assertivas de gestores, especialistas, autoridades governamentais, assim como, envolver ambientalistas, estudantes e outros interessados no tema da preservação à natureza, para se garantir melhores condições de vida da população e a sustentabilidade do planeta. Destacar-se aqui o relevante papel que tem o profissional sanitarista, por lidar com a busca de respostas e soluções para os problemas e necessidades sociais em saúde das coletividades. 
Artigo original

Hegemonia - Revista Eletrônica do Programa de Mestrado em Direitos Humanos, Cidadania e Violência/Ciência Política do Centro Universitário Unieuro

ISSN: $1809-1261$

UNIEURO, Brasília, número 26, Janeiro a Junho de 2019, pp. 66-94.

Marco Histórico-Conceitual

A literatura que trata das atividades eletivas entre meio ambiente e saúde remontam desde a antiguidade. Hipócrates no ano 400 a.C. em sua publicação "Dos Ares, Águas e Lugares" buscou explicações com fundamento no racional, sobre a influência do meio ambiente na ocorrência de doenças na população. O Pai da Medicina No Ocidente pondera o seguinte:

Para conhecer a doença é necessário estudar o homem em seu estado normal e a relação com o meio ambiente em que vive e investigar ao mesmo tempo, as causas que perturbam o equilíbrio entre o homem, o meio exterior e social (HIPOCRATES apud ADAM, 2005).

No século XIV, o filósofo e médico suíço Philippus Aureolus Theophrastus Bombastus von Hohenheim, Philippus Aureolus Theophrastus Bombastus von Hohenheim, melhor conhecido como Paracelso, mostrou a relação existente entre certas doenças físicas, a profissão e o meio ambiente. Considerado o pai da saúde ambiental, ele contribuiu para a desmistificação do modelo biomédico e trouxe importantes contribuições para o novo paradigma do processo saúde-doença. Seus estudos apontavam que éramos frutos do meio em que vivíamos. Em lugar de considerar saúde e doença como componentes de um sistema binário, como presença/ausência, considerava saúde-doença como um processo no qual o ser humano passa por múltiplas situações, que exigem do seu meio interno um trabalho de compensações e adaptações sucessivas (HANS e SMITH, 2000).

O processo acelerado de industrialização e urbanização em meados dos séculos XVIII e XIX desencadeou vários efeitos nocivos para a saúde decorrente da problemática ambiental. John Snow, em 1855, realizou um ensaio sobre a maneira de transmissão da cólera em Londres, conseguindo comprovar em seus estudos a relação da contaminação da água com a epidemia de cólera. Nesse estudo, o autor faz uma descrição detalhada do desenvolvimento da epidemia de cólera usando-se de raciocínio lógico para explicar sua transmissão (teoria do contágio), tudo isso, décadas antes do início das descobertas no campo da microbiologia e, portanto, do isolamento e identificação do Vibrio Cholerae como agente 
Artigo original

Hegemonia - Revista Eletrônica do Programa de Mestrado em Direitos Humanos, Cidadania e Violência/Ciência Política do Centro Universitário Unieuro

ISSN: 1809-1261

UNIEURO, Brasília, número 26, Janeiro a Junho de 2019, pp. 66-94.

etiológico da cólera, contrariando, portanto, a teoria dos miasmas, até então vigente (CAMERON e JONES, 1983).

Foi a partir do século XX que a inter-relação da saúde com o meio ambiente se inseriu nas preocupações da saúde pública. A Organização Mundial de Saúde conceitua saúde como o completo bem-estar físico, social e mental. Sabe-se que este conceito tem gerado polêmicas devido apresentar um alto grau de utopia, dado que a ideia de bem-estar depende, em grande medida das condições econômicas, sociais e culturais em que cada pessoa está inserida. De fato, o completo bem estar pode significar situações ou realidades diferentes, variando portanto de país para país, assim como no interior de cada um deles, dependendo de suas condições culturais, sociais e econômicas. Por estas e outras razões, parece prudente e necessário ponderar que o conceito em questão é assumido neste estudo, tendo, porém certas limitações de alcance e precisão. No fundo, trata-se de constatar, junto a muitos especialistas do tema, que a noção de saúde não alude somente a ausência de doença. Pelo contrário a noção de saúde também se refere, como pondera Paim (1994), à base sobre a qual se constrói a felicidade dos indivíduos, apoiada na solidariedade, alegria de viver e prazer como suporte para sua realização como pessoa.

Hoje, as preocupações com a degradação do meio ambiente e sua correlação com o processo de adoecimento humano ganham proporções internacionais já que condições meteorológicas extremas provocadas pelo aquecimento global, assim como, o uso indiscriminado de poluentes químicos, não têm sido controlado. Tal situação está comprometendo às condições de vida, saúde, felicidade e bem-estar dos seres humanos no planeta.

Nesse contexto, entende-se que a saúde deve ser entendida também como um direito humano fundamental. O seu cumprimento é um dever essencial da sociedade e do Estado, razão pela qual este estudo se relaciona também com o papel da sociedade e do Estado frente às políticas públicas e suas contribuições para a preservação ambiental e qualidade de vida da população em geral.

A Constituição Federal de 1988 em seu Capítulo VI faz a seguinte menção sobre o meio ambiente nos seguintes termos: 
Artigo original

Hegemonia - Revista Eletrônica do Programa de Mestrado em Direitos Humanos, Cidadania e Violência/Ciência Política do Centro Universitário Unieuro

ISSN: 1809-1261

UNIEURO, Brasília, número 26, Janeiro a Junho de 2019, pp. 66-94.

Art. 225. Todos têm direito ao meio ambiente ecologicamente equilibrado, bem de uso comum do povo e essencial à sua qualidade de vida, impondo-se ao poder público e à coletividade o dever de defendê-lo e preservá-lo para as presentes e futuras gerações.

Assim, representa um marco na Legislação Ambiental, pois foi responsável por sistematizar a matéria do meio ambiente, e estabelecer a saúde ambiental, como um direito fundamental do indivíduo (BRASIL, 1988). Vale ressaltar ademais que a Organização Mundial da Saúde descreveu que "saúde ambiental é o campo de atuação da saúde pública que se ocupa das formas de vida, das substâncias e das condições em torno do ser humano, que podem exercer alguma influência sobre a sua saúde e o seu bem-estar” (BRASIL, 1999).

A pesquisa "Quem é quem na saúde ambiental no Brasil?”, realizada por Freitas et al. (2009), e que objetivava identificar e caracterizar grupos de pesquisas e organizações da sociedade civil atuantes no campo da saúde ambiental, mostrou que os estudos relacionados ao meio ambiente e saúde tiveram seu maior crescimento na passagem do século XX para o XXI. Isso devido aos resultados concretos das políticas de consolidação da pesquisa científica aplicadas no Brasil nas últimas décadas, com destaque para: a) o aumento do financiamento; b) a formação de mestres e doutores; c) a ampliação dos programas de pós-graduação e dos trabalhos publicados em periódicos científicos. Nesse estudo, constatou-se ademais que 73\% dos grupos de pesquisa que compõem o universo levantado foram criados a partir do ano 2000, ou seja, quando a questão ambiental já se encontrava consolidada e as questões relacionadas à saúde ambiental iniciavam seu processo de institucionalização no setor saúde, mais precisamente na vigilância em saúde.

Neste sentido, destaca-se a relevância e pertinência do campo interdisciplinar da saúde coletiva, por ser a área de produção de conhecimento e saberes em saúde, destinadas a atenção das coletividades. Paim e Almeida Filho (2013), colocam que a saúde coletiva deve ser entendida como campo científico, onde se produzem saberes e conhecimentos acerca do objeto saúde e onde operam distintas disciplinas que o contemplam sob vários ângulos. A saúde coletiva também se relaciona com os âmbitos de práticas, onde se realizam ações em diferentes organizações e instituições por diversos agentes (especializados ou não) dentro e fora do espaço convencionalmente reconhecido como setor saúde. Seu objeto de estudo concentra-se em investigar as necessidades sociais em saúde. Em outras palavras, estuda os 
Artigo original

Hegemonia - Revista Eletrônica do Programa de Mestrado em Direitos Humanos, Cidadania e Violência/Ciência Política do Centro Universitário Unieuro

ISSN: 1809-1261

UNIEURO, Brasília, número 26, Janeiro a Junho de 2019, pp. 66-94.

problemas de saúde que repercutem nas coletividades, operando nas intervenções de promoção da saúde e prevenção das doenças, na busca por maior qualidade de vida para a população em geral.

Vale ressaltar que, apesar dos esforços de se implantar ações e práticas de conservação ambiental para responder às necessidades de saúde das coletividades, beneficiando, assim, o maior número de pessoas possíveis, a saúde coletiva ainda deve enfrentar desafios. Dentre esses, destacam-se: a) garantir o efetivo funcionamento do princípio da intersetorialidade; b) fomentar a formação de mais profissionais nesta linha; c) intensificar a produção de conhecimentos na área; d) incentivar a transversalidade das ações; e) ampliar a empregabilidade do sanitarista nesse campo específico; f) aumentar a demanda no mercado de trabalho ambiental em relação ao sanitarista; dentre outros. Cumpre acrescentar que trabalhar na área da preservação do meio ambiente é complexo, amplo e desafiador, devido principalmente aos interesses de diferentes atores políticos, sociais e econômicos que lucram com sua exploração.

Dias (2015), em seu livro Eco Perceção, explica que o modelo de desenvolvimento utilizado hoje é a raiz do problema, por induzir as pessoas ao consumo, aumentando a pressão sobre os recursos naturais e consequentemente degradando o meio ambiente. Indica ainda que, o modelo de desenvolvimento econômico baseado no consumismo está atrelado às forças econômicas e políticas como o agronegócio e mineradoras cuja lógica de negócio visa basicamente o lucro, sem comprometimento com o desenvolvimento de estudos e pesquisas que impulsionem inovações tecnológicas geradoras de tecnologias menos agressivas ao meio ambiente.

É importante mencionar que por meio ambiente neste estudo, deve-se entender o conjunto de componentes físicos, químicos, biológicos e sociais capazes de causar efeitos diretos ou indiretos, em um prazo curto ou longo, sobre os seres vivos e as atividades humanas (CNUMAD, 2001). Considerando o exposto, reconhece-se que as preocupações com a preservação e conservação do meio ambiente em toda a sua amplitude e magnitude de concepção são relativamente recentes. 
Artigo original

Hegemonia - Revista Eletrônica do Programa de Mestrado em Direitos Humanos, Cidadania e Violência/Ciência Política do Centro Universitário Unieuro

ISSN: 1809-1261

UNIEURO, Brasília, número 26, Janeiro a Junho de 2019, pp. 66-94.

As conferências mundiais sobre meio ambiente e seus legados

Pode-se verificar que os principais acontecimentos e eventos científicos mundiais que marcaram ou marcam a trajetória ambiental tiveram início somente na década de sessenta, como a criação do Clube de Roma, em 1968. Esse Clube tinha como objetivo analisar as consequências do incremento do crescimento econômico mundial com o crescente uso dos recursos naturais. Dessa discussão, resultou o relatório "Os limites do Crescimento" (PORTAL DA EDUCAÇÃO, 2012), cuja preocupação apontava para as consequências que o rápido crescimento socioeconômico, acompanhado do uso irracional dos recursos naturais, podia implicar para o planeta. Paralelamente a essas discussões, cresciam as preocupações que os riscos ocupacionais podiam trazer para a saúde dos trabalhadores. Aqui ganha força a disciplina epidemiologia ambiental cujos temas mais pesquisados giram em torno da poluição do ar, solo e água; bem como ao uso de pesticidas, metais pesados e aumento dos números de casos de câncer (REGO e BARRETO, 2013).

Outro marco histórico importante ocorreu em 05 de junho de 1972, com a realização da $1^{\text {a }}$ Conferência Mundial sobre o Homem e o Meio Ambiente. Conhecida também por Conferência de Estocolmo por ter sido realizada nessa cidade da Suécia. Este evento consistiu na primeira reunião de dimensão global a abordar assuntos vinculados ao cuidado e proteção do meio ambiente. É importante destacar que o Programa das Nações Unidas para o Meio Ambiente - PNUMA foi criado nessa ocasião, tornando-se a primeira agência ambiental de abrangência mundial. Ademais, essa data de 05 de junho foi a escolhida para se celebrar o dia mundial do meio ambiente (PORTAL BRASIL, 1972).

O Relatório "Nosso Futuro Comum”, organizado pela primeira ministra da Noruega, Gro Harlem Brundtland, por isso também conhecido como o Relatório de Brundtland, foi apresentado em 1987, sendo também um documento importante nas discussões sobre o meio ambiente, pois apresenta e divulga os problemas socioeconômicos e ambientais produzidos pelo desenvolvimento econômico voltado para os interesses do mercado. O relatório traz informações sobre a destruição da camada de ozônio e aquecimento global, sendo esses, novos assuntos a serem tratados. Foi nesse documento que o conceito de "desenvolvimento sustentável" ganhou mais força e visibilidade desde quando foi pensado na década de 1970. Vale esclarecer que por desenvolvimento sustentável deve se 
Artigo original

Hegemonia - Revista Eletrônica do Programa de Mestrado em Direitos Humanos, Cidadania e Violência/Ciência Política do Centro Universitário Unieuro

ISSN: 1809-1261

UNIEURO, Brasília, número 26, Janeiro a Junho de 2019, pp. 66-94.

entender "o desenvolvimento que satisfaz as necessidades das gerações presentes sem comprometer a capacidade de as gerações futuras satisfazerem as suas próprias necessidades" (COMISSÃO MUNDIAL SOBRE MEIO AMBIENTE E DESENVOLVIMENTO, 1987).

Cinco anos após o Relatório de Brundtland, ocorreu na cidade do Rio de Janeiro um outro importante evento, foi a Conferência das Nações Unidas sobre Meio Ambiente e Desenvolvimento (CNUMAD), conhecida também por Rio-92, Eco-92 ou Cúpula da Terra. Nesse evento, foi discutido o tema do desenvolvimento sustentável e as questões ambientais, que já vinham sendo abordados desde a conferência de Estocolmo. No entanto, na Conferência Rio-92, ficou acertado que os países precisariam receber tanto apoio tecnológico quanto financeiro para conseguirem alcançar modelos de desenvolvimento mais sustentável, incluindo a diminuição dos padrões de consumo. Nessa conferência, os representantes dos países participantes do evento assumiram mais comprometimento com as questões ambientais, o que resultou na "Agenda 21", documento onde se instituiu a importância dos países de se empenharem e pensarem de forma global e local a respeito dos problemas socioambientais (CNUMAD, 2001).

O Protocolo de Quioto foi outro grande marco no que diz respeito ao tema ambiental. Assinado em 1997, em Quioto no Japão, entrou em vigor somente em 2005, depois que a Rússia o ratificou. Esse protocolo trata da redução de emissão de gases que agravam o efeito estufa, considerado como causa principal do aquecimento global. De acordo com Protocolo de Quioto (1997), cada país participante tem a responsabilidade de limitar e reduzir as emissões de gases de efeito estufa a fim de favorecer o desenvolvimento sustentável (PROTOCOLO DE QUIOTO, 1997).

A “Cúpula da Terra sobre Sustentabilidade e Desenvolvimento", também conhecida de Rio+ 10, ocorreu no ano de 2002, em Joanesburgo, na África do Sul. Foi um evento de grande porte, onde reuniram-se ambientalistas de todo o mundo para discutirem e revisar as metas da Agenda 21. Nesse encontro prevaleceu nas discussões a necessidade de conciliação entre o desenvolvimento socioeconômico e a preservação e cuidado do meio ambiente (CONFERÊNCIA DAS NAÇÕES UNIDAS SOBRE DESENVOLVIMENTO SUSTENTÁVEL, 2012). 
Artigo original

Hegemonia - Revista Eletrônica do Programa de Mestrado em Direitos Humanos, Cidadania e Violência/Ciência Política do Centro Universitário Unieuro

ISSN: 1809-1261

UNIEURO, Brasília, número 26, Janeiro a Junho de 2019, pp. 66-94.

Outra importante conferência das nações unidas foi a de Copenhaga, realizada na Dinamarca, em 2009, cujo tema central das discussões eram as Mudanças Climáticas provocadas pelo aquecimento global. As deliberações nesse encontro giraram em torno de combater o avanço da temperatura global, assim como auxiliar os países em desenvolvimento através de apoio financeiro para que os mesmos pudessem também atuar em prol da redução do aquecimento planetário (PORTAL BRASIL, 2009).

Outro evento marcante sobre meio ambiente ocorreu no Brasil, foi a Rio +20 ou Cúpula da Terra que ocorreu no Rio de Janeiro em junho de 2012. Teve como objetivo analisar e renovar os compromissos para o desenvolvimento sustentável. Desse evento não resultou nenhum documento novo, os especialistas somente avaliaram os progressos das principais cúpulas sobre a temática ambiental (CONFERÊNCIA DAS NAÇÕES UNIDAS SOBRE DESENVOLVIMENTO SUSTENTÁVEL, 2012).

O último evento de importância global que ocorreu sobre o tema do meio ambiente foi o Acordo Climático Global, chamado de Acordo de Paris, que aconteceu em 2015, na França. Foi um acordo que buscou envolver quase todos países do mundo com o intuito de reduzir os impactos das mudanças climáticas, ou aquecimento global. Ficou acordado entre os representantes de cada país a necessidade de se traçar um plano nacional para ajudar na redução de emissões de gás carbono e frear os efeitos do aquecimento global a partir de 2020. Segundo a Organização das Nações Unidas no Brasil (ONUBR), esse acordo é um chamado aos governos para se prepararem para implementar a Agenda 2030 do Desenvolvimento Sustentável (ONUBR, 2015).

O Brasil e o meio ambiente: algumas conquistas

É importante destacar que a ocorrência de eventos ambientais internacionais em solo brasileiro serviu de incentivo para o Brasil se organizar ambientalmente em termos de políticas públicas setoriais. Foi assim que, em 1973, foi criada a Secretaria Especial do Meio Ambiente (SEMA). Oito anos depois ocorreu a promulgação da Lei n 6938 de 31 de agosto de 1981, que dispõe sobre a Política Nacional do Meio Ambiente (PNMA) e que tem como objetivo garantir a preservação, melhoria e recuperação da qualidade ambiental favorável a 
Artigo original

Hegemonia - Revista Eletrônica do Programa de Mestrado em Direitos Humanos, Cidadania e Violência/Ciência Política do Centro Universitário Unieuro

ISSN: 1809-1261

UNIEURO, Brasília, número 26, Janeiro a Junho de 2019, pp. 66-94.

vida, no intuito de promover o desenvolvimento socioeconômico, com zelo nacional e à proteção da dignidade da vida humana (BRASIL, 1981).

Logo, em 1989, foi criado o Instituto Brasileiro de Meio Ambiente e dos Recursos Naturais Renováveis (IBAMA), com o intuito de controlar e reduzir o elevado número de queimadas na Amazônia. A criação do Ministério do Meio Ambiente (MMA) em novembro de 1992, ou seja, três anos depois da criação do IBAMA foi de grande importância, já que este ministério tem como missão promover princípios e estratégias, a proteção e recuperação do meio ambiente, o uso sustentável dos recursos naturais, valorização dos serviços ambientais, bem como inserção de políticas públicas (BURSZTYN e PERSEGONA, 2008).

Foi assim que no ano 1999 foi promulgada a Lei no 9795 de 27 de abril de 1999 e seu regulamento, bem como o Decreto n ${ }^{\circ} 4.281$, de 25 de junho de 2002, estabelecendo a Política Nacional de Educação Ambiental (PNEA). Ambas normas obrigam as escolas a trabalharem o tema do meio ambiente de forma transversal nas aulas ministradas. Uma publicação, de 2007, do Ministério da Educação (MEC) juntamente com o Ministério do Meio Ambiente (MMA), explana a importância da educação ambiental nas escolas, gerando grande expectativas, para os educadores, ambientalistas e professores no que diz respeito a formação de gerações mais sustentáveis (FERRARI e ZANCUL, 2016).

Outro grande marco na busca por se garantir o cuidado e proteção do meio ambiente foi a aprovação em 2010 da Lei no 12.305/10, que institui a Política Nacional de Resíduos Sólidos (PNRS). Essa política tem como metas a eliminação dos lixões em todas as cidades do país, criando instrumentos de planeamento nos níveis nacional, estadual, microrregional, intermunicipal e metropolitano e municipal valorizando os catadores de materiais recicláveis, tanto na logística reversa quanto na coleta seletiva (BRASIL, 2010). Vale ressaltar que os catadores de resíduos sólidos atuam como verdadeiros agentes ambientais, mas pelo tipo de atividade que executam, em contato direto com o lixo, são marginalizados e excluídos socialmente além de serem extremamente vulneráveis a doenças relacionadas ao meio ambiente e trabalho que estão expostos. 
Artigo original

Hegemonia - Revista Eletrônica do Programa de Mestrado em Direitos Humanos, Cidadania e Violência/Ciência Política do Centro Universitário Unieuro

ISSN: 1809-1261

UNIEURO, Brasília, número 26, Janeiro a Junho de 2019, pp. 66-94.

Meio ambiente e saúde: um diálogo cada vez necessário

Como já mencionado anteriormente, desde a revolução industrial a utilização irracional dos recursos naturais tornou-se massiva em quase todo o mundo. Como consequência, observa-se hoje graves e preocupantes problemas ambientais, muitos anunciados previamente por estudiosos e ambientalistas e que se não forem reparados a curto e médio prazo pode comprometer seriamente a vida no planeta. Destaca-se aqui: a) poluição do ar por gases gerados, principalmente, pela queima de combustíveis fósseis (carvão mineral, gasolina e diesel e indústrias; b) poluição de rios, lagos, mares e oceanos provocada por despejos de esgotos e lixo, acidentes ambientais como vazamento de petróleo; c) poluição do solo provocada por contaminação por agrotóxicos, fertilizantes e produtos químicos, ademais de descarte incorreto de lixo; d) queimadas em matas e florestas como forma de ampliar áreas para pasto ou agricultura; e) desmatamento com o corte ilegal de árvores para comercialização de madeira; f) esgotamento do solo e perda da fertilidade pela agricultura; g) diminuição e extinção de espécies animais, provocadas pela caça predatória e destruição de ecossistemas; h) escassez de água potável para o consumo humano, causado pelo desperdício, contaminação e poluição dos recursos hídricos; i) acidentes com materiais radioativos que causam contaminação do solo por centenas de anos como por exemplos os acidentes nucleares de Chernobyl (1986), na Usina Nuclear de Fukushima no Japão (2011) e o episódio do vazamento de Césio 137 em Goiânia (1987); j) aquecimento global, causado pela grande quantidade de emissão de gases do efeito estufa; k) destruição da camada de ozônio, provocada pela emissão de gases como o clorofluorcarbono, no meio ambiente (MARQUES, 2016).

As condições ambientais globais extremas e em larga escala vêm preocupando cientistas e ambientalistas em todo o mundo. Estudo de Lé Queré et al. (2015) apontam que foram despejados na atmosfera no referido ano 32,3 Gton de CO2. Desse total, 26\% foi absorvido pelos oceanos; $30 \%$ pelo solo; e 44\% se acumularam na atmosfera. Dentre os países que mais contaminaram a atmosfera com a emissão de gás carbono em megatoneladas 
Artigo original

Hegemonia - Revista Eletrônica do Programa de Mestrado em Direitos Humanos, Cidadania e Violência/Ciência Política do Centro Universitário Unieuro

ISSN: 1809-1261

UNIEURO, Brasília, número 26, Janeiro a Junho de 2019, pp. 66-94.

em 2013 aparecem: $1^{\circ}$ lugar a China - 7.216; $2^{\circ}$ Estados Unidos - 6.538; $3^{\circ}$ Índia $-2.272 ; 4^{\mathrm{a}}$ lugar aparece a Rússia - 1963; 5 Japão 1.203; $6^{\circ}$ lugar o Brasil - 1.144; $7^{\circ}$ Alemanha 916; em $8^{\circ}$ lugar aparece o Canadá com 692 megatoneladas.

Resulta curioso e, às vezes, até paradoxal a falta de diálogo e comunicação entre órgãos governamentais, setores econômicos, sociedade civil sobre as consequências de todo esse processo de degradação do meio ambiente para a saúde da população, com ênfase no cumprimento de políticas públicas acompanhadas de fiscalização. Obviamente, estas questões são extremamente relevantes e merecem uma análise mais aprofundada, pois todos os aspectos supra citados podem desencadear sérios problemas de saúde com danos irreversíveis.

A maioria das pessoas vive hoje nas cidades que ocupam apenas $4 \%$ da superfície da terra, mas em contraparte, consomem $75 \%$ dos recursos naturais do planeta, ademais de retratar um número cada vez maior de excluídos, muitos, provenientes da zona rural onde perderam espaço com o crescimento das inovações tecnológicas no campo. O baixo nível de escolaridade dessas pessoas contribui para que, muitas vezes, permaneçam à margem do sistema, enfrentando situações como: desemprego, pobreza, miséria, humilhação, violência, estresse, doença e desagregação familiar (DIAS, 2015).

A falta de infraestrutura de saneamento básico é outro problema vivido pelas cidades que não têm conseguido suportar o aumento massivo de águas negras produzidas, onde muitas vezes são lançadas de forma desregulada a céu aberto contaminando as ruas das cidades, o solo, os lenções freáticos e provocando, adoecimento da população. Dados do Instituto Trata Brasil indicam que hoje, mais de 35 milhões de brasileiros vivem sem ter acesso a água potável, mais de 100 milhões não dispõem de coleta de esgoto, e somente 40\% dos esgotos do país são tratados (INSTITUTO TRATA BRASIL, 2015).

Gestão pública ambiental: alguns desafios fundamentais

No Brasil prevalece hoje, tanto as doenças do desenvolvimento - doenças crônicas degenerativas - como as doenças do subdesenvolvimento provocadas por falta de 
Artigo original

Hegemonia - Revista Eletrônica do Programa de Mestrado em Direitos Humanos, Cidadania e Violência/Ciência Política do Centro Universitário Unieuro

ISSN: 1809-1261

UNIEURO, Brasília, número 26, Janeiro a Junho de 2019, pp. 66-94.

saneamento básico como as verminoses, diarreias infeciosas, cólera, leptospirose, hepatite A, febre-amarela, malária, esquistossomose e as provocadas pelo mosquito Aëdes Aegypti como dengue, febre chikungunya e zika que estão entre as mais preocupantes atualmente no Brasil (AMBIENTE BRASIL, 2016).

O saneamento básico é fundamental para a vida humana, sendo um conjunto de medidas que compreendem tratamento de água, canalização e tratamento de esgotos, limpeza pública, coleta e tratamento de resíduos orgânicos e regularização de aterros sanitários. Importante ressaltar que saneamento básico está ligado também aos determinantes sociais. Segundo a Comissão Nacional sobre os Determinantes Sociais da Saúde (CNDSS), os DSS são os fatores sociais, econômicos, culturais, étnicos/raciais, psicológicos e comportamentais que influenciam na ocorrência de problemas de saúde e seus fatores de risco na população (BUSS e PELLEGRINI, 2007). A vulnerabilidade da população está relacionada às condições ambientais em que está exposta. Quanto mais pobre, sem escolaridade, com moradias inadequadas, e sem cobertura de saneamento básico, mais suscetível às doenças.

Neste contexto a Lei Federal no 11.445, de 05 de janeiro de 2007, estabelece diretrizes nacionais para o saneamento básico. Seus princípios fundamentais são: a universalização do acesso; integralidade, compreendida como o conjunto de todas as atividades e componentes de cada um dos diversos serviços de saneamento básico, propiciando à população o acesso na conformidade de suas necessidades e maximizando a eficácia das ações e resultados; abastecimento de água, esgotamento sanitário, limpeza urbana e manejo dos resíduos sólidos realizados de formas adequadas à saúde pública e à proteção do meio ambiente; disponibilidade, em todas as áreas urbanas, de serviços de drenagem e de manejo das águas pluviais adequados à saúde pública e à segurança da vida e do patrimônio público e privado (BRASIL, 2007).

Abastecimento de água- A média nacional de atendimento urbano por rede de água é de 82,5\%. Em relação aos estados, o índice médio de atendimento urbano por rede de água indica valores acima de 90\% em 18 estados, Paraná, Minhas Gerais, Roraima, Mato Grosso do Sul, São Paulo, Paraíba, Mato Grosso, Santa Catarina, Piaú, Tocantins, Rio Grande do Norte, Goiás, Bahia, Rio Grande do Sul, Sergipe, Alagoas, Espírito Santo e Rio de Janeiro, mais o Distrito Federal. Na faixa de $80 \%$ a 90\%, aparecem outros 3, Amazonas, Ceará e Pernambuco; na faixa logo abaixo, entre 60\% e 80\%, apenas o Maranhão; e na penúltima 
Artigo original

Hegemonia - Revista Eletrônica do Programa de Mestrado em Direitos Humanos, Cidadania e Violência/Ciência Política do Centro Universitário Unieuro

ISSN: 1809-1261

UNIEURO, Brasília, número 26, Janeiro a Junho de 2019, pp. 66-94.

faixa, de 40\% a 60\%, situam-se Acre, Pará e Rondônia. Por fim, somente o Amapá aparece na menor faixa, abaixo de 40\% (SNIS, 2014).

Esgotamento sanitário- A média nacional com coleta de esgoto é de 48,6\%. Segundo o Sistema Nacional de Informações sobre Saneamento (SNIS, 2014), no Norte do Brasil apenas 14,36\% do esgoto é tratado, e o índice de atendimento total é de 7,88\%, sendo considerada como pior situação entre todas as regiões. O Nordeste apenas $28,8 \%$ do esgoto é tratado, Sudeste 43,9\%, e Região Sul, 43,9\%. Dados ainda apontam que aproximadamente 1,2 bilhão de $\mathrm{m}^{3}$ de esgotos vão parar na natureza. A falta de esgotamento sanitário além de impactar diretamente o meio ambiente ainda compromete a saúde e diminui a esperança de vida ao nascer e expectativa de vida da população.

Limpeza urbana e manejo dos resíduos- Quanto à coleta seletiva e disposição final dos resíduos, a Lei no 12.305/2010 define, em seu Artigo 3º destinação final ambientalmente adequada, a destinação de resíduos que inclui a reutilização, a reciclagem, a compostagem, a recuperação e o aproveitamento energético ou outras destinações admitidas pelos órgãos competentes do Sistema Nacional do Meio Ambiente (Sisnama), do Sistema Nacional de Vigilância Sanitária (SNVS) e do Sistema Único de Atenção à Sanidade Agropecuária (Suasa). Essas normas abordam sobre a disposição final, observando regulações operacionais específicas de modo a evitar danos ou riscos à saúde pública e à segurança e a minimizar os impactos ambientais adversos (Brasil, 2010a). A PNSB considerou como unidades de destinação final aterros controlados, aterros sanitários, unidades de compostagem, unidades de tratamento por incineração, unidades de triagem para reciclagem, vazadouros a céu aberto, vazadouros em áreas alagáveis, locais não fixos (na edição de 2000) e outras unidades de destinação. No Brasil, apenas 58\% dos municípios apresentam destinação adequada de resíduos urbanos (RSU). Para agravar ainda mais a situação, a quantidade de RSU destinada a locais inadequados totalizou 29.659.170 toneladas no ano de 2014, que seguiram para lixões ou aterros controlados, os quais do ponto de vista ambiental pouco se diferenciam dos lixões, pois não possuem o conjunto de sistemas necessários para a proteção do meio ambiente e da saúde pública (ABRELPE, 2014).

Nos países desenvolvidos as doenças veiculadas pela poluição da água, do ar e do solo parecem estar mais sobre controle. O que vem preocupado as autoridades desses países são os casos de câncer provocados pela contaminação da água por metais pesados, o que 
Artigo original

Hegemonia - Revista Eletrônica do Programa de Mestrado em Direitos Humanos, Cidadania e Violência/Ciência Política do Centro Universitário Unieuro

ISSN: 1809-1261

UNIEURO, Brasília, número 26, Janeiro a Junho de 2019, pp. 66-94.

responde por $1 \%$ a 4\% casos de cânceres segundo dados do Instituto Nacional do Câncer (2011).

Estudo de Rego e Barreto (2013), aponta que nos países desenvolvidos a poluição do ar é responsável por $20 \%$ das infecções respiratórias já nos países em desenvolvimento esse número chega a $42 \%$. Colocam ademais que o retardamento mental causado pelo chumbo é em 100\% atribuído a contaminação do meio ambiente. Um agravante para esta exposição é a destinação inadequada de lixo eletrônico nos lixões o que compromete a saúde dos catadores e suas famílias e da população da área adjacente pela contaminação do lençol freático.

No Brasil, o rompimento da barragem em Mariana, da mineradora Samarco, em 2015, causou várias mortes e tornou áreas urbanas improprias para ocupação humana. A lama com os rejeitos da produção de minério de ferro (dentre eles o chumbo) atingiu o rio Doce, onde interrompeu o abastecimento de água em algumas cidades mineiras e em municípios do Espírito Santo, além de provocar a morte de animais e a perda de biodiversidade ao longo do rio e do mar aonde a lama atingiu. O rompimento da barragem de Mariana é considerado pelas autoridades um dos maiores desastres ambientais do Brasil (EVANGELISTA, 2013). As consequências para a saúde humana desse acidente ainda são imprevisíveis, mas, pela quantidade de metais pesados como: chumbo, Arsênio e manganês encontrados nas amostras de águas analisadas, as estimativas são preocupantes.

Outro aspecto ambiental que tem preocupado os pesquisadores e especialistas são os adoecimentos provocados por fatores externos como por exemplo, as radiações infravermelhas e ultra violeta emitidas pelos raios solares. Sabe-se que a exposição prolongada e sem proteção a essas radiações pode favorecer o aparecimento de câncer de pele e de lábio. Preocupam também, exposições ocupacionais ao asbesto, arsênio, benzeno, sílica, radiação, agrotóxico, fumaça do tabaco por serem comprovadamente carcinogênicas.

Ademais, os riscos de adoecimento por consequência da contaminação ambiental podem ser duradouros. Nos casos específicos de contaminação por substâncias radioativas, essa pode durar até algumas centenas de anos. Vale destacar aqui, a catástrofe ambiental provocada pela explosão das bombas atômicas nas cidades japonesa de Hiroshima e Nagasaki, no Japão no século XX, cuja incidência e a mortalidade por câncer da população nessas regiões, são altas até os dias atuais (INSTITUTO NACIONAL DO CÂNCER, 2011). 
Artigo original

Hegemonia - Revista Eletrônica do Programa de Mestrado em Direitos Humanos, Cidadania e Violência/Ciência Política do Centro Universitário Unieuro

ISSN: 1809-1261

UNIEURO, Brasília, número 26, Janeiro a Junho de 2019, pp. 66-94.

Cabe mencionar também que, em 1987, na cidade de Goiânia ocorreu um dos maiores acidentes radioativos do país e o maior do mundo ocorrido fora das usinas nucleares, foi o acidente com o isótopo Césio 137 classificado como de nível 5, ou seja, com consequências a longo alcance. $\mathrm{O}$ manuseio por catadores de materiais recicláveis de um aparelho de radioterapia encontrado em uma clínica abandonada vitimou centenas de pessoas. Estudos indicam que em 2012, ou seja, 25 anos após o acidente, cerca de 104 pessoas já haviam morrido de câncer em consequência da contaminação, e cerca de 1600 vinham padecendo de outras enfermidade provocadas pela contaminação radioativa (EVANGELISTA, 2013).

O uso massivo e indiscriminado de agrotóxico nas lavouras é outro grande desafio ambiental hoje. A produção de alimentos em grande escala para atender ao mercado exportado e também abastecer o mercado interno vem contaminando com resíduos químicos o solo, a água e também os alimentos. Sabe-se que é muito difícil identificar a influência do solo contaminado na saúde da população. No entanto, evidências científicas apontam que o uso irracional de fertilizantes, pesticidas e outras substâncias químicas que contenham metais pesados como o arsênio, antimônio, cádmio, chumbo e mercúrio podem causar danos renais e neurológicos principalmente em crianças e idosos (REGO e BARRETO, 2013).

Segundo dados da Associação Brasileira de Saúde Coletiva, 70\% dos alimentos in natura consumidos no país estão contaminados por agrotóxicos. Desses, $28 \%$ contém substâncias não autorizadas pela Agência Nacional de Vigilância Sanitária- ANVISA. Dentre os produtos que mais utilizam agrotóxico no Brasil estão: soja (40\%), milho (15\%), cana-deaçúcar e algodão (10\% cada), cítricos (7\%), café, trigo e arroz (3\% cada), feijão $(2 \%)$, batata $(1 \%)$ tomate $(1 \%)$, maça $(0,5 \%)$, banana $(0,2 \%)$. As demais culturas consumiram $3,3 \%$ do total de 852,8 milhões de litros de agrotóxicos pulverizados nas lavouras brasileiras em 2011 (CARNEIRO, 2015). Esses dados assustam já que o consumo frequente desses produtos expõem as pessoas a risco de adoecimento. Cabe aqui à disciplina epidemiologia ambiental um papel importantíssimo, no sentido de medir a magnitude, frequência e duração da exposição e os reais riscos que isso implica para a saúde humana, fomentado os tomadores de decisão sobre o tema com informações mais precisas e pontuais. 
Artigo original

Hegemonia - Revista Eletrônica do Programa de Mestrado em Direitos Humanos, Cidadania e Violência/Ciência Política do Centro Universitário Unieuro

ISSN: 1809-1261

UNIEURO, Brasília, número 26, Janeiro a Junho de 2019, pp. 66-94.

Segundo Friedrich (2013), existe uma forte barreira de proteção que inviabiliza a suspensão do uso dessas substâncias no Brasil e que está diretamente relacionado com os interesses de mercado relacionados à indústria do agrotóxico. Segundo dados do Instituto Nacional do Câncer (2015), enquanto nos últimos 10 anos o mercado mundial desse setor cresceu 93\%, no Brasil esse crescimento foi de 190\%, saltando de 2 bilhões de dólares para mais de 7 bilhões entre 2001 e 2008, alcançando valores recordes de 8,5 bilhões de dólares em 2011. Hoje, estima-se que o consumo médio de agrotóxico por brasileiro chega a 5,2 kg de veneno por ano.

Sabe-se que o consumo de alimentos com resíduos de agrotóxicos está altamente associado à incidência de câncer e doenças genéticas. Estudo de Beecham e Seneff (2016) aponta para outra estimativa preocupante. Segundo suas pesquisas, há uma íntima correlação entre o uso indiscriminado do Roundup, herbicida da MONSANTO -empresa multinacional de agricultura e biotecnologia, sediada nos Estados Unidos - feito à base de Glicosato, e os aumentos de casos de autismos em crianças recém nascidas nos últimos anos.

Diante do exposto, constata-se que a contaminação ambiental tem muito impacto na saúde da população e deve ser vista de acordo com a grande magnitude de seus danos. Para atender às demandas desse complexo campo, é imprescindível a formação de profissionais orientados por uma concepção interdisciplinar que conjugue elementos do modelo biomédico com conhecimentos oriundos do domínio das ciências humanas, sociais e ambientais, deslocando-se de uma preocupação eminentemente individual para uma atuação na esfera coletivo/populacional e ambiental. Destaca-se aqui o papel do sanitarista e seu olhar pelas necessidades sociais em saúde das coletividades.

Meio ambiente e saúde no Brasil: repensando o papel do sanitarista

Por princípio, a atuação no campo de saber e prática da saúde coletiva exige sempre o envolvimento de equipes multiprofissionais com um enfoque interdisciplinar. No caso da saúde e meio ambiente a disciplina epidemiologia ambiental é considerada uma das referências nesse estudo por contemplar um conjunto de fatores que envolvem agentes biológicos como água, sistema de esgoto sanitário, destino final do lixo, condições ambientais 
Artigo original

Hegemonia - Revista Eletrônica do Programa de Mestrado em Direitos Humanos, Cidadania e Violência/Ciência Política do Centro Universitário Unieuro

ISSN: 1809-1261

UNIEURO, Brasília, número 26, Janeiro a Junho de 2019, pp. 66-94.

nos domicílios e manuseio de alimentos. Por epidemiologia ambiental deve-se entender o estudo da distribuição de eventos relacionados com o estado de saúde em populações humanas que tenham na sua determinação fatores ambientais, sejam eles físicos, biológicos ou químicos (REGO E BARRETO, 2013).

Ademais da epidemiologia ambiental, outra disciplina que apoia a discussão sobre o meio ambiente e saúde, é a disciplina comumente conhecida como Saúde, Ambiente e Trabalho. Essa disciplina busca correlacionar doenças com o meio ambiente em que o trabalhador está inserido. Ou seja, busca investigar se as condições ambientais onde o trabalhador exerce suas funções podem desencadear a longo, médio ou curto prazo alguma doença correlacionada. Usa-se como parâmetros de análise: ambiente físico (temperatura, pressão, ruído, vibração, irradiação, altitude); ambiente químico (produtos manipulados, vapores, gases tóxicos, poeiras, fumos, fumaças); ambiente biológico (vírus, bactérias, parasitas e fungos); condições de higiene e segurança; dentre outros.

Destaca-se aqui, a urgência de se envolver e sensibilizar um maior número possível de pessoas (especialistas ou não) para o tema meio ambiente e saúde. Com ênfase, o profissional sanitarista, cuja formação inclui eixos que perpassa pela política, planejamento, gestão, epidemiologia, avaliação em saúde, promoção e educação em saúde, vigilância em saúde e saúde ambiental, dentre outras disciplinas (FGSC-ABRASCO, 2015). O campo de atuação desse profissional tem gerado grandes expectativas sociais e ambientais, tanto no contexto internacional, nacional, regional e local, pois a formação interdisciplinar que recebe, possibilita auxiliar de forma mais assertivas nas decisões tomadas em prol das coletividades e com a excelência técnica que se precisa. Ademais, desde a perspectiva da gestão socioambiental, tem-se a expectativa de que que esses profissionais podem se destacar no setor público por priorizar nas suas decisões as coletividades em prol dos favoritismos e loteamentos políticos tradicionalmente observados nos serviços públicos no Brasil. Sobre o tema, Berté (2013), faz a seguinte menção:

A "ecologização" da administração pública embora tenha crescido nas últimas décadas, ainda preserva uma visão pré-ambientalista e pré-sustentabilista, em parte por falta de uma internalização dessa cultura institucional nova e também porque o modelo de administração atual e menos profissional e mais político. Os Ministérios, assim como as Secretarias, tanto nos governos estaduais, como nos municipais são 
Artigo original

Hegemonia - Revista Eletrônica do Programa de Mestrado em Direitos Humanos, Cidadania e Violência/Ciência Política do Centro Universitário Unieuro

ISSN: $1809-1261$

UNIEURO, Brasília, número 26, Janeiro a Junho de 2019, pp. 66-94.

loteamentos políticos. Há, portanto, uma necessidade urgente de se alterar essa conjuntura.

No caso específico, a inclusão de sanitaristas em instâncias administrativas superiores, pode promover grandes transformações na gestão, principalmente em Ministérios, Secretarias e outras áreas diretamente relacionadas ao meio ambiente e à saúde. Lembre-se que estudos comprovam que $25 \%$ da carga global de doença no mundo estão relacionadas com causas ambientais e mais de 33\% da carga global de doenças em crianças são devidas a causas ambientais modificáveis (PRÜSS-ÜSTÜN e CORVALAN, 2006).

Cabe destacar mais uma vez o importante papel que tem o sanitarista, no sentido de fornecer as bases científicas e tecnológicas para a tomada de decisão no que diz respeito ao cuidado e proteção da saúde humana, com ênfases no papel das agências de vigilância sanitária na tomada de decisões sobre a deliberação e autorização para consumo humano dos alimentos derivados da biotecnologia, também comumente conhecidos como alimentos transgênicos. As consequências e seus efeitos sobre a saúde a longo prazo ainda não são totalmente elucidados, gerando controvérsias e polêmicas entre os pesquisadores. O mesmo ocorre com os efeitos dos campos eletromagnéticos gerados por aparelhos de micro-ondas e celulares que apesar de terem sido associados em alguns estudos a casos de glioma, neuroma acústico e meningioma, seguem, todavia, sem comprovação científica (AHLBOM, 2009).

Cabe considerar aqui o tema da justiça ambiental e o princípio da precaução que consiste no fato de mesmo com a ausência de certeza científica formal, a existência de qualquer forma de evidências que sinalizem para a existência de risco requer a implementação de ações que possam prevenir esse dano (BLANK, 2006).

Outro desafio a ser superado é romper com a noção de que o desenvolvimento deve estar associado a ideia de produção e consumo. Nesta linha de pensamento, precisaríamos de cinco planetas terras para suprir as necessidades de consumo, caso os países em desenvolvimento passassem a consumir como os países desenvolvidos como afirma Rigotto e Augusto (2007). Precisa-se mudar ou atrelar a ideia de desenvolvimento dos países, considerando a capacidade dos mesmos em preservar seus recursos naturais. Só assim, podese pensar em fidelidade ao termo sustentabilidade, muitas vezes usado como modismo e forma de atrair a admiração de simpatizantes das causas ambientais (BOFF, 2014). 
Artigo original

Hegemonia - Revista Eletrônica do Programa de Mestrado em Direitos Humanos, Cidadania e Violência/Ciência Política do Centro Universitário Unieuro

ISSN: $1809-1261$

UNIEURO, Brasília, número 26, Janeiro a Junho de 2019, pp. 66-94.

\section{Considerações finais}

A partir do exposto neste estudo, infere-se que há pelo menos três cenários prospectivos: a) cenário inercial; b) cenário otimista; e c) cenário pessimista.

a) Cenário Inercial: As tendências atuais continuariam como estão, com leis nem sempre aplicadas de forma integral e com a atuação limitada do sanitarista no campo do meio ambiente.

b) Cenário Otimista: Coincidiria com um maior interesse da sociedade e do poder público brasileiro ao tema ambiental, tornando o assunto mais visível. Nesse caso, a consciência ambiental do povo brasileiro se tornaria muito apurada e efetiva, sobretudo no que diz respeito ao saneamento básico, a legislação e a educação ambiental. Neste contexto, o trabalho do sanitarista seria reconhecido e valorizado tanto no contexto da empregabilidade como na formulação e implementação de políticas públicas setoriais como também na iniciativa privada.

c) Cenário Pessimista: Os acordos internacionais seriam descumpridos por algumas potências mundiais e em termos nacionais as regulações ambientais acabariam sendo negligenciadas e descumpridas tanto por agentes públicos e privados e as contribuições do sanitarista poderiam ser desdenhadas, com negativo impacto na empregabilidade e desempenho desse profissional.

$\mathrm{Na}$ opinião dos autores desse trabalho, e a partir dos três cenários apresentados, acredita-se que a tendência mais provável de desenvolvimento futuro passaria em algum ponto, entre o cenário inercial e o otimista. Nesse diapasão, entende-se que existe um espaço importante para o sanitarista contribuir na sensibilização da sociedade brasileira para os temas socioambientais.

Nesse sentido, é importante reconhecer alguns avanços concretos da interdependência entre meio ambiente e saúde e nesse diapasão destacam-se por exemplo: criações e massificação de instituições para o cuidado com o meio ambiente; realização de eventos locais, nacionais e internacionais sobre meio ambiente; fomentar a mobilização mundial; promover a inovação tecnológica na busca por fontes renováveis de energia, 
Artigo original

Hegemonia - Revista Eletrônica do Programa de Mestrado em Direitos Humanos, Cidadania e Violência/Ciência Política do Centro Universitário Unieuro

ISSN: 1809-1261

UNIEURO, Brasília, número 26, Janeiro a Junho de 2019, pp. 66-94.

garantir processos industriais mais limpos; reduzir o consumo e melhorar a qualidade dos combustíveis; fornecimento de produtos químicos menos agressivos; promover práticas agrícolas de baixo impacto ambiental; e o desenvolvimento de inovadores processos de gestão ambiental como a ISO 14001, que consiste em uma série de normas elaboradas por mais de 200 países. A aquisição do selo internacional ISO 14001 significa o compromisso da instituição em garantir uma produção nos seus estabelecimentos com baixo impacto ambiental. Destacam-se ainda, a educação ambiental; criação de unidades de conservação e manejo de bacias hidrográficas; intensificação do processo de reaproveitamento e reciclagem apoiados na coleta seletiva de resíduos, dentre outros.

Entretanto, ainda são muitos os desafios como: investir no alfabetismo ambiental por meio de ações educativas; ordenar o processo de urbanização nos grandes centros; incentivar e fomentar a pesquisa e inovação baseadas na ética intergeracional e ambiental; valorizar posturas de hábitos de vida saudáveis, buscar o apoio da mídia; sensibilizar a população para o consumo responsável; propor políticas públicas sustentáveis; fiscalizar e punir ações individuais e coletivas que agridam o meio ambiente; dentre outros.

Nesse sentido, parece pertinente insistir que os profissionais formados em saúde coletiva, ou sanitarista, tem um importante papel a desempenhar tanto no contexto nacional como internacional.

No contexto nacional esse profissional tem um amplo campo de atuação que perpassa pelas três esferas governamentais (local, estadual e federal), com destaque para órgãos como: Ministérios, Secretarias, Institutos, Núcleos, Universidades, Centros de Pesquisas, Fundações, Agências Reguladoras, Autarquias, assim como, em Organizações Não Governamentais (ONGs) e na iniciativa privada.

No âmbito internacional, o sanitarista ambiental pode trabalhar como auditor de órgãos de gestão ambiental como por exemplo a ISO 14001; além de consultor de Agências Internacionais ligadas ao meio ambiente; Programas das Nações Unidas sobre o meio ambiente como o PNUMA; Organização Pan-americana de Saúde (OPAS); Organizações Civis sem fins lucrativos, dentre outros.

Em todas essas frentes, o sanitarista pode atuar como gestor, assessor, mediador, pesquisador e educador, buscando minimizar ações ambientais degradadoras e causadoras de 
Artigo original

Hegemonia - Revista Eletrônica do Programa de Mestrado em Direitos Humanos, Cidadania e Violência/Ciência Política do Centro Universitário Unieuro

ISSN: $1809-1261$

UNIEURO, Brasília, número 26, Janeiro a Junho de 2019, pp. 66-94.

adoecimentos nos seguintes campos: a) saneamento ambiental; b) gerenciamento de resíduos sólidos; c) educação ambiental; d) estudos dos ecossistemas urbanos; e) gestão de recursos hídricos; f) fontes renováveis de energia; dentre outras.

Sabe-se que os desafios são grandes e perpassa por questões de ordem política, econômica, cultural e social. O debate está aberto, espera-se com este estudo ampliar a discussão e contribuir para a edificação de uma sociedade onde a utilização dos recursos naturais seja feita de forma racional, apoiada no princípio da justiça ambiental e baseada na ética intergeracional, de forma que as gerações futuras também venham a usufruir do que a natureza nos dispõem hoje.

Referências

AHLBOM, Anders, et al. Epidemiologic evidence on mobile phones and tumor risk: a review. ICNIRP (International Commission for Non-Ionizing Radiation Protection) Standing Committee on Epidemiology. Epidemiologia, Vol. 20 (5), Setembro de 2009, p. 639652.

AMBIENTE BRASIL. Doenças causadas pela falta de Saneamento. 2016. Disponível em: http://ambientes.ambientebrasil.com.br/agua/artigos_aguas_urbanas/doencas_causadas_ pela_falta_de_saneamento.html> Acesso em: 01 de maio de 2017.

ASSOCIAÇÃO BRASILEIRA DE EMPRESAS DE LIMPEZA PÚBLICA E RESÍDUOS ESPECIAIS [ABRELPE]. Panorama dos Resíduos Sólidos no Brasil. 2014. Disponível em: <http://www.abrelpe.org.br/Panorama/panorama2014.pdf> Acesso em: 25 de abril de 2017.

BEECHAM, James E., e SENEFF, Stephanie. Is there a link between autism and glyphosateformulated herbicides? Journal of Autism, Vol. 3 (1), 2016, DOI: http://dx.doi.org/10.7243/2054-992X-3-1.

BERTÉ, Rodrigo. Gestão Socioambiental no Brasil: Uma Análise Ecocêntrica. Curitiba: Editora Intersaberes, 2013. 
Artigo original

Hegemonia - Revista Eletrônica do Programa de Mestrado em Direitos Humanos, Cidadania e Violência/Ciência Política do Centro Universitário Unieuro

ISSN: 1809-1261

UNIEURO, Brasília, número 26, Janeiro a Junho de 2019, pp. 66-94.

BLANK, Martin. The Precautionary Principle must be guided by EMF research. Electromagn Biol Med., Vol. 25(4), 2006, p. 203-8.

BOFF, Leonardo. Sustentabilidade: o que é, o que não é. $3^{\mathrm{a}}$ ed. Rio de Janeiro: Vozes, 2014.

BRASIL. Ministério das Cidades. Sistema Nacional de Informações Sobre Saneamento. Brasília, DF. 2014. Disponível em: http://www.snis.gov.br/ Acesso em 05/05/2017.

BRASIL. Ministério do Meio Ambiente. Política Nacional de Resíduos Sólidos. Diário Oficial da União, Brasília, DF. 2010. Disponível em: < http://www.mma.gov.br/pol\%C3\%ADtica-deres $\%$ C3\%ADduos-s\%C3\%B3lidos>. Acesso em 03 de mai de 2017.

BRASIL. Lei Federal n. 11.445, de 5 de janeiro de 2007, Brasilia: Governo Federal, 2007.

BRASIL. Ministério da Saúde. Política nacional de saúde ambiental para o setor saúde. Brasília: Secretaria de Políticas de Saúde, 1999. Disponível em: < http://www.planalto.gov.br/ccivil_03/leis/L9795.htm> Acesso em 30 de abr de 2017.

BRASIL. Constituição da República Federativa do Brasil. Brasília, 1988. Disponível em: http://www.planalto.gov.br/ccivil_03/constituicao/ConstituicaoCompilado.htm. Acesso em: 08 de maio de 2017.

BRASIL. Politica Nacional do Meio Ambiente. Lei n 6938, de 31 de agosto de 1981. Disponível em: < http://www.planalto.gov.br/ccivil_03/leis/L6938.htm>. Acesso em: 05 de maio de 2017.

BRASIL. Ministério da Saúde. Água Brasil: sistema de avaliação da qualidade da água, saúde e saneamento, 1966. Disponível em: http://www.ibama.gov.br/cinia/index.php?id_menu66.

BURSZTYN, Marcel, e PERSEGONA, Marcelo. A grande transformação ambiental: Uma cronologia da dialética homem-natureza. Rio de Janeiro: Garamond, 2008.

BUSS, Paulo, e PELLEGRINI, Alberto. A saúde e seus determinantes sociais. Physis, Vol. 17 (1), 2007, p. 77-93.

CAMERON, Donald, e JONES, Ian G. John Snow, the Broad Street Pump and Modern Epidemiology. International Journal of Epidemiology, Vol. 12 (4), 1983, p. 393-396. 
Artigo original

Hegemonia - Revista Eletrônica do Programa de Mestrado em Direitos Humanos, Cidadania e Violência/Ciência Política do Centro Universitário Unieuro

ISSN: 1809-1261

UNIEURO, Brasília, número 26, Janeiro a Junho de 2019, pp. 66-94.

CARNEIRO, Fernando Ferreira (Org.). Dossiê ABRASCO: Uma alerta sobre o impacto dos agrotóxicos na saúde. Rio de Janeiro: EPSJV e São Paulo: Expressão popular, 2015.

COMISSÃO MUNDIAL SOBRE MEIO AMBIENTE E DESENVOLVIMENTO. Nosso

Futuro Comum, 1987. Disponível em: <http://www.un-documents.net/wced-ocf.htm> Acesso em: 02 de maio de 2017.

CNUMAD. Conferência das Nações Unidas sobre Meio Ambiente e Desenvolvimento, Agenda 21. Curitiba: Ipardes, 2001.

\section{CONFERENNCIA DAS NAÇÕES UNIDAS SOBRE DESENVOLVIMENTO} SUSTENTÁVEL (RIO+20). The Future $W$ e Want, Rio de Janeiro. 2012. Disponível em: $<$ http://www.rio20.gov.br/documentos/documentos-da-conferencia/o-futuro-quequeremos/at_download/the-future-we-want.pdf>. Acesso em 10 de maio de 2017.

CONFERÊNCIA DAS NAÇÕES UNIDAS SOBRE DESENVOLVIMENTO SUSTENTÁVEL (RIO+10). Declaração de Joanesburgo sobre Desenvolvimento Sustentável. Disponível em: < http://www.onu.org.br/rio20/img/2012/07/unced2002.pdf>. Acesso em: 15 de maio de 2017.

DIAS, Genebaldo Freire. EcoPercepção: Um resumo didático dos cenários e desafios socioambientais. $2^{\mathrm{a}}$ ed. São Paulo: Gaia, 2015.

EVANGELISTA, Itelmar R. Acidente radiológico, césio-137: Uma abordagem crítica sobre os limites da responsabilidade ambiental reconhecida pelo tribunal regional federal da primeira região, em razão do fato ocorrido em Goiânia. Revista de Estudos Jurídicos, Vol. 17 (25), 2013, p. 373-402.

FERRARI, Alexandre Harlei, e ZANCUL, Maria Cristina de Senzi. Aproximações entre os contextos locais e nacionais em práticas de educação ambiental na escola. Revista brasileira de educação ambiental, Vol.1 (1), 2016, p. 66-84.

FGSC-ABRASCO. MINUTA DAS DIRETRIZES CURRICULARES NACIONAIS DO CURSO DE GRADUAÇÃO EM SAÚDE COLETIVA. Rio de Janeiro: Abraco, 2015, Disponível em: <https://www.abrasco.org.br/site/wp-content/uploads/2015/06/DCNCGSC-versao-junho-2015.pdf>, consulta em: 15 de maio de 2017. 
Artigo original

Hegemonia - Revista Eletrônica do Programa de Mestrado em Direitos Humanos, Cidadania e Violência/Ciência Política do Centro Universitário Unieuro

ISSN: 1809-1261

UNIEURO, Brasília, número 26, Janeiro a Junho de 2019, pp. 66-94.

FREITAS, Carlos M., et al. Quem é quem na saúde ambiental brasileira? Identificação e caracterização de grupos de pesquisas e organizações da sociedade civil. Revista Ciência e Saúde Coletiva, Vol. 14 (6), 2009, p. 2071-2082.

FRIEDRICH, Karen. Desafios para avaliação toxicológica de agrotóxicos no Brasil: Desregulação endócrina e imunotoxicidade. Sociedade, Ciencia e Tecnologia, Vol.1 (2), 2013, p. $2-15$.

GUERRA, Antônio, e CUNHA, Sandra B. da (Org.). Impactos ambientais urbanos no Brasil. $4^{\text {a }}$ ed. Rio de Janeiro: Bertrand Brasil, 2006.

HANS C. Binswanger, e SMITH, Kirk R. Paracelsus and Goethe: founding fathers of environmental health. Bulletin of the World Health Organization, Vol. 78 (9), 2000, p. 1162-1165. HIPOCRATES. On airs, on waters, and places, 2005 [400 AC]. Disponível em: http://classics.mit.edu/Hippocrates/airwatpl.1.1.html. Acesso em 24 de abril de 2017.

INSTITUTO NACIONAL DO CANCER. Brasil lidera o ranking de consumo de agrotóxicos, Rio de Janeiro, 2015, Disponível em: http://www2.inca.gov.br/wps/wcm/connect/comunicacaoinformacao/site/home/namidi a/brasil_lidera_ranking_consumo_agrotoxicos. Acesso em 10 de maio de 2017.

INSTITUTO NACIONAL DO CÂNCER. ABC do câncer : abordagens básicas para o controle do câncer. Rio de Janeiro, 2011. Disponível em: $<$ http://bvsms.saude.gov.br/bvs/publicacoes/abc_do_cancer.pdf>. Acesso em 03 de maio de 2017.

INSTITUTO TRATA BRASIL, Ranking do Saneamento 2015. 2015. Disponível em: http://www.tratabrasil.org.br/ranking-do-saneamento-2015. Acesso em 15 de maio de 2017.

KARIATSUMARI. Sueli N. Saneamento Básico: Apostila de Técnico em Gestão

Ambiental. Colégio CETÈS, 2007. Disponível em: <http://pt.scribd.com/doc/42317923/apostila-saneamento>. Acesso em 23 out. 2015.

LE QUÉRÉ, Corine, et al. Global Carbon Budget 2014. Earth Syst. Sci. Data, Vol. 7, 2015, p. $47-85$.

MARQUES, Luiz. Capitalismo e colapso ambiental. 2 ed. Campinas: Unicamp, 2016. 
Artigo original

Hegemonia - Revista Eletrônica do Programa de Mestrado em Direitos Humanos, Cidadania e Violência/Ciência Política do Centro Universitário Unieuro

ISSN: 1809-1261

UNIEURO, Brasília, número 26, Janeiro a Junho de 2019, pp. 66-94.

MARTINS, Clitia et al. Da Rio-92 à Rio+20: Avanços e retrocessos da agenda 21 no Brasil. Indicadores Econômicos FEE, Vol. 42 (3), 2015, p. 97-108.

ONU. Acordo de Copenhague. Disponível em: $<$ http://ecen.com/eee75/eee75p/copenhague_acordo.htm> Acesso em: 23 de mai de 2017.

ONUBR. Acordo de Paris. 2016. Disponível em: < https:// nacoesunidas.org/onu-esclareceduvidas-a-respeito-do-novo-acordo-climatico-adotado-pelos-estados-membros-na-cop21/ $>$ Acesso em: 23 de mai de 2016.

ONUBR. Acordo de Paris sobre o clima. Conferência das partes, 2017. Disponível em: https://nacoesunidas.org/acordodeparis/. Acesso em 14 de maio de 2017.

PAIM, Jairnilson. Recursos humanos em saúde: Problemas crônicos e desafios agudos. São Paulo: Faculdade de Saúde Pública /USP, 1994.

PAIM, Jairnilson, e ALMEIDA FILHO, Naomar. Saúde Coletiva: Teoria e Prática. , Rio de Janeiro: Editora Medibook 2013.

PORTAL BRASIL Conferência das Nações Unidas sobre o Meio Ambiente Humano 1972. Meio Ambiente, Acordos Globais, 2012. Disponível em: http://www.brasil.gov.br/meio-ambiente/2012/01/acordos-globais. Acesso em: 10 de maio de 2017

PORTAL BRASIL. Acordos Globais. Conferência de Copenhagen, 2009. Disponível em www.brasil.gov.br > Meio Ambiente > 2012 > $01>$ Acordos globais. Acesso em: 14 de maio de 2017.

PORTAL DA EDUCACAO. O Clube de Roma 1972. Relatório: Os limites do crescimento. Portal da Educação, 2012. Disponível em https://www.portal da educação.com.br/conteúdo/artigos/biologia/o-clube-de-roma-1972/20122. Acesso em 15 de maio de 2017.

PROTOCOLO DE QUIOTO. Ministério da Ciência e Tecnologia: Protocolo de Quioto, 1997. Disponível em: <http://www.mct.gov.br/upd_blob/0012/12425.pdf/> Acesso em: 08 maio 2017. 
Artigo original

Hegemonia - Revista Eletrônica do Programa de Mestrado em Direitos Humanos, Cidadania e Violência/Ciência Política do Centro Universitário Unieuro

ISSN: 1809-1261

UNIEURO, Brasília, número 26, Janeiro a Junho de 2019, pp. 66-94.

PRÜSS-ÜSTÜN, Annette, e CORVALÁN, Carlos. Preventing disease through healthy environments, Paris: OMS, 2006.

REGO, Rita, e BARRETO, Maurício. Epidemiologia ambiental. In: Naomar de Almeida Filho e Maurício Barreto (orgs.). Epidemiologia e Saúde: Fundamentos, métodos, aplicações. Rio de Janeiro: Editora Guanabara, 2013, p. 363-374.

RIGOTTO, Raquel Maria, e AUGUSTO, Lia Giraldo da Silva. Saúde e ambiente no Brasil: desenvolvimento, território e iniqüidade social. Cad. Saúde Pública, Vol. 23 (4), 2007, pp. S475-S485. 